\title{
The burden of hepatitis $C$ virus infection is growing: A Canadian population-based study of hospitalizations from 1994 to 2004
}

\author{
Robert P Myers MD ${ }^{1}$, MingFu Liu PhD ${ }^{2}$, Abdel Aziz M Shaheen MD MPH ${ }^{1}$
}

RP Myers, MF Liu, AA Shaheen. The burden of hepatitis C virus infection is growing: A Canadian population-based study of hospitalizations from 1994 to 2004. Can J Gastroenterol 2008;22(4):381-387.

BACKGROUND: Nearly $1 \%$ of Canadians are infected with the hepatitis $\mathrm{C}$ virus (HCV). Simulation analyses have suggested that $\mathrm{HCV}$ will place an increasing burden on the health care system as the infected population ages, but supportive clinical data are limited. OBJECTIVES: To study temporal trends in HCV-related hospitalizations and predictors of increased health care utilization from a Canadian population-based perspective.

METHODS: An administrative hospitalization database from the Calgary Health Region was used to identify patients who were admitted for HCV between 1994 and 2004. The primary outcomes were liver-related HCV hospitalizations, length of stay, hospital costs and in-hospital mortality. Average annual growth rates in outcomes were calculated and subgroup analyses were conducted according to age, sex and HIV/HCV coinfection status.

RESULTS: Between 1994 and 2004, there were 4002 HCV-related hospitalizations; $22 \%$ were liver-related. Liver-related hospitalizations, lengths of stay and in-hospital mortality increased approximately fourfold or an average of $15 \%$ to $18 \%$ annually $(\mathrm{P}<0.0005)$. Patients aged 40 to 59 years and HIV/HCV coinfected patients experienced the largest average annual growth rates $(19 \%$ to $27 \%$ and $30 \%$ to $40 \%$, respectively; $\mathrm{P}<0.0005$ ), reflecting the accelerated natural history of HCV in these subgroups. Hospital costs for liverrelated HCV hospitalizations increased by an average of $41 \%$ annually $(\mathrm{P}=0.001)$ between 2000 and 2004 . The average annual increase in liver-related hospitalizations remained significant in a sensitivity analysis, even when $75 \%$ of $\mathrm{HCV}$ cases were underreported in 1994.

CONCLUSIONS: The present studies' findings confirm the growing burden of HCV on the Canadian health care system. Strategies to prevent $\mathrm{HCV}$ infection and maximize the dissemination and most effective use of potentially curative antiviral therapies are necessary to reduce these trends.

Key Words: Burden of illness; Cirrhosis; Database; Epidemiology; Outcome study; Trends

\section{Le fardeau de l'infection par le virus de l'hépatite $\mathrm{C}$ augmente : Une étude canadienne en population des hospitalisations entre 1994 et 2004}

HISTORIQUE : Près de $1 \%$ des Canadiens sont infectés par le virus de l'hépatite C (VHC). Selon les analyses de simulation, le VHC exercera un fardeau croissant sur le système de santé avec le vieillissement de la population infectée, mais les données cliniques corroboratives sont limitées.

OBJECTIFS : Étudier les tendances temporelles dans les hospitalisations reliées au VHC et les prédicteurs d'augmentation de l'utilisation des services de santé selon une perspective en population canadienne.

MÉTHODOLOGIE : Une base de données administrative de la population de la région sanitaire de Calgary a permis de repérer les patients hospitalisés en raison du VHC entre 1994 et 2004. Les issues primaires étaient des hospitalisations causées par des troubles hépatiques du VHC, la durée d'hospitalisation, les frais hospitaliers et la mortalité en milieu hospitalier. Les auteurs ont calculé les taux de croissance annuels moyens des issues et menés des analyses de sous-groupe selon l'âge, le sexe et le statut de co-infection par le VIH et le VHC.

RÉSULTATS : Entre 1994 et 2004, on a recensé 4002 hospitalisations reliées au VHC, dont $22 \%$ reliées au foie. Les hospitalisations reliées à des troubles hépatiques, la durée d'hospitalisation et la mortalité en milieu hospitalier ont presque quadruplé, soit une moyenne de $15 \%$ à $18 \%$ chaque année $(\mathrm{P}<0,0005)$. Les patients de 40 à 59 ans et ceux coinfectés par le VIH et le VHC ont subi les plus forts taux de croissance moyens annuels (19\% à $27 \%$ et $30 \%$ à $40 \%$, respectivement; $\mathrm{P}<0,0005)$, reflétant l'évolution naturelle accélérée du VHC au sein de ces sous-groupes. Les frais hospitaliers des hospitalisations du VHC reliées à des troubles hépatiques ont augmenté d'une moyenne de $41 \%$ par année $(\mathrm{P}=0,001)$ entre 2000 et 2004. L'augmentation annuelle moyenne d'hospitalisations reliées à des troubles hépatiques est demeurée importante dans une analyse de sensibilité, même lorsque 75 \% des cas de VHC étaient sous-déclarés en 1994.

CONCLUSIONS : Les résultats de la présente étude confirment le fardeau croissant du VHC sur le système de santé canadien. Des stratégies pour prévenir l'infection par le VHC et maximiser la diffusion et l'utilisation de thérapies antivirales au potentiel curatif s'imposent pour limiter ces tendances.

Chea hronic hepatitis $\mathrm{C}$ virus ( $\mathrm{HCV}$ ) infection is a major public health problem. An estimated 170 million individuals worldwide (3\% of the population) (1) and 250,000 Canadians $(0.8 \%)$ are anti-HCV positive (2). The majority (approximately $80 \%$ ) are chronically infected and may progress to cirrhosis,

end-stage liver disease and hepatocellular carcinoma (3). Although the natural history of HCV typically follows a protracted course, with complications occurring decades after initial infection, several risk factors, including older age, male sex $(4,5)$ and HIV coinfection $(6,7)$ are associated with accelerated

${ }^{1}$ Liver Unit, Division of Gastroenterology, Department of Medicine, University of Calgary; ${ }^{2}$ Health System Analysis Unit, Quality, Safety and Health Information, Calgary Health Region, Calgary, Alberta

Correspondence: Dr Robert P Myers, Liver Unit, University of Calgary, 6D22, Teaching, Research and Wellness Building, 3280 Hospital Drive

Northwest, Calgary, Alberta T2N 4N1. Telephone 403-592-5049, fax 403-592-5090, e-mail rpmyers@ucalgary.ca

Received for publication October 11, 2007. Accepted November 19, 2007 
disease progression. Cirrhosis caused by chronic HCV accounts for at least 1000 deaths annually in Canada (8) and has become the leading indication for liver transplantation (9).

Considering the large pool of infected individuals, the current burden of HCV on the Canadian health care system is relatively modest. However, as the population of infected individuals ages and their disease has time to progress, more patients are expected to develop complications and place increasing strain on the health care system. Several studies using mathematical models have projected a marked increase in rates of HCV-related hepatic complications (10-15). For example, Zou et al (10) projected that the number of cases of HCVrelated cirrhosis, liver failure, hepatocellular carcinoma and liver-related deaths would approximately double between 1998 and 2008. Although Pohani et al (8) reported a 3.7-fold increase in the age-standardized mortality rate for non-A, non-B hepatitis (primarily caused by HCV) (16) in Canada between 1979 and 1997, surprisingly little clinical data have been reported to support the remainder of these alarming projections (17).

The objective of the present study was to describe temporal trends in HCV-related hospitalizations in a large Canadian health region between 1994 and 2004. By describing recent changes in hospitalizations for $\mathrm{HCV}$, we provide a frame of reference for future projections of the burden of this disease on the Canadian health care system.

\section{METHODS}

Patients hospitalized for HCV infection between April 1, 1994 and March 31, 2005 (fiscal years 1994 through 2004) were identified by using an administrative hospitalization database maintained in the Calgary Health Region (CHR) (18). The CHR is one of the largest fully integrated, publicly funded health care systems in Canada, providing virtually all medical and surgical care to approximately 1.1 million residents of Calgary and surrounding communities in southern Alberta. Included within the region are 12 academic and community hospitals, including four large hospitals within the city of Calgary. Each hospital separation within the administrative database contains up to 50 diagnosis codes (18). If a patient had a primary or secondary diagnosis of $\mathrm{HCV}$ infection (International Classification of Diseases, Ninth Revision, Clinical Modification [ICD-9-CM] codes 070.41, 070.44, 070.51, 070.54, V02.62 [19]; and International Classification of Diseases, Tenth Revision [ICD-10] codes B17.1, B18.2, Z22.51 [20]), the hospitalization was defined as HCV-related. Because HCV-related complications were the predominant concerns in the present study (rather than unrelated conditions requiring admission in $\mathrm{HCV}$-positive patients), liverrelated hospitalizations were also identified. A hospitalization was considered to be liver-related if the principal diagnosis was $\mathrm{HCV}$; there was any diagnosis of cirrhosis, portal hypertension, other sequelae of liver disease, hepatic encephalopathy, ascites, hepatorenal syndrome, variceal bleeding, hepatocellular carcinoma or cholangiocarcinoma; or the patient had undergone a liver transplant $(21,22)$.

\section{Validation of HCV diagnoses}

To validate the diagnoses of $\mathrm{HCV}$, the medical records of 100 randomly selected patients were reviewed by a physician blinded to the administrative data (AMS). According to the validation study, the sensitivity, specificity, positive predictive value and negative predictive value of the administrative data for confirmed HCV infection (defined as anti-HCV positivity) were $97 \%$ ( 56 of 58), $98 \%$ (41 of 42 ), $98 \%$ (56 of 57) and $95 \%$ (41 of 43), respectively.

\section{Analysis of under-reporting of $\mathrm{HCV}$}

Because HCV antibody testing did not become available until 1989 (23), it is unlikely that widespread testing occurred by 1994. Thus, the hospitalization frequencies that were observed in the present study likely underestimated the actual numbers by greater proportions at the beginning of the study. Because the rate of HCV testing and reporting increased over time, the growth rates that were observed in the present study may have overestimated the increase in hospitalizations for $\mathrm{HCV}$. Therefore, a sensitivity analysis was conducted to consider the potential impact of under-reporting. As described by Grant et al (22), as a baseline scenario, it was hypothesized in the present study that $50 \%$ of cases were under-reported in 1994 and that under-reporting fell each year by a fixed amount, so that all cases were reported by 2004 . The initial rate of underreporting was varied between $25 \%$ and $75 \%$. As a control group, hospitalizations for alcoholic cirrhosis (ICD-9-CM 571.2 [19]; ICD-10 K71.3 [20]) were examined. Because alcoholic cirrhosis was not as likely as HCV to be under-reported during the early years of the study, differences in hospitalization frequencies for these conditions likely reflect both the effects of under-reporting and differences in disease burden (22).

\section{Statistical analyses}

For all HCV- and alcoholic cirrhosis-related hospitalizations, admittance frequencies, total days in the hospital and inhospital mortality were examined as measures of disease burden. Poisson regression, with the independent variable being a timetrend indicator for fiscal year, was used to assess the rates of change of these outcomes over the interval (24). These models were adjusted for the overall number of hospitalizations in the CHR, which grew 1.0\% annually between 1994 and 2004. The results changed minimally when the models were adjusted for the growth of the CHR population (data not shown). Where the number of events permitted, subgroup analyses were performed according to sex, age (in 20-year categories) and HIV coinfection (ICD-9-CM 042, 079.53, V08 [19]; and ICD-10 B20-B24, Z21 [20]), because these factors have been demonstrated to impact HCV disease progression (4-7).

Total hospital costs were also examined, which were available in $93 \%$ to $97 \%$ of admissions between 2000 and 2004, based on expenses accrued from direct and indirect patient care (excluding physician fees). All costs were adjusted to 2007 Canadian dollars using the Consumer Price Index (25). Simple linear regression models of hospital costs versus fiscal year (2000 to 2004) were used to assess average annual changes in total costs.

Hospitalization details were compared using MannWhitney, $\chi^{2}$ and Fisher's exact tests, as appropriate. Stata v8.0 (StataCorp LP, USA) and SAS v9.1 (SAS Institute, Inc, USA) were used for all analyses. The study was approved by the Conjoint Health Research Ethics Board at the University of Calgary (Calgary, Alberta).

\section{RESULTS}

From 1994 through 2004, there were 4002 HCV hospitalizations in the CHR; 869 (22\%) were liver-related. The number of HCV-related hospitalizations increased significantly during 


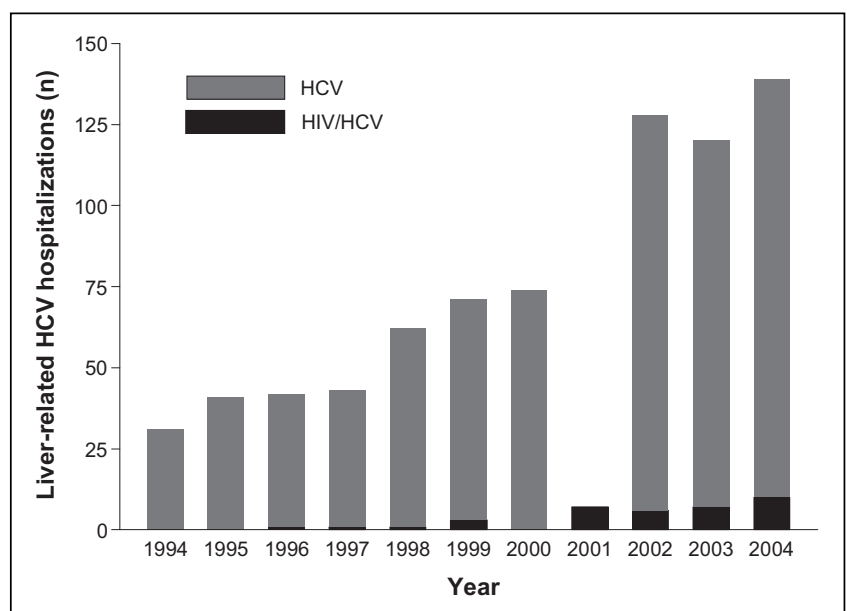

Figure 1) Annual number of liver-related hepatitis C virus (HCV) hospitalizations in the Calgary Health Region (1994 through 2004), stratified according to HIV status

the study interval (Figures 1 and 2; $\mathrm{P}<0.0005$ ). In contrast, hospitalizations for alcoholic cirrhosis remained stable (Figure 3; $\mathrm{P}>0.05$ ). Table 1 provides average annual growth rates for HCV- and alcoholic cirrhosis-related hospitalizations and days in the hospital during the 11-year study period. The admittance frequencies and lengths of stay increased significantly for HCV-related hospitalizations, while alcoholic cirrhosis-related admissions remained stable and lengths of stay increased slightly. Similarly, total hospital costs for liver-related admissions increased an average of $41.2 \%$ (95\% CI $31.0 \%$ to $51.4 \%$ ) annually between 2000 and 2004 for patients with HCV, but remained stable for those with alcoholic cirrhosis (average annual change, $-4.6 \%$; $95 \%$ CI $-11.5 \%$ to $2.4 \%$ ). Importantly, the observed increases in the number of days in the hospital and costs for HCV resulted from more frequent hospitalizations as opposed to longer lengths of stay. The median (interquartile range [IQR]) length of stay for liver-related HCV hospitalizations was not significantly different between the first and final three years of the study period (1994 to 1996 versus 2002 to 2004: seven days [three to 12 days] versus seven days [four to 14 days]; $\mathrm{P}=0.14$ ).

Similar results were obtained with respect to in-hospital mortality. The average number of in-hospital deaths in patients with liver-related admissions increased 16.2\% (95\% CI $8.3 \%$ to $24.7 \%$ ) annually in patients with $\mathrm{HCV}$, but remained stable in those with alcoholic cirrhosis $(0.1 \%$; $95 \%$ CI $-2.5 \%$ to $2.8 \%)$. This increase in HCV-related deaths was entirely attributable to the growth in the number of hospitalizations, as opposed to an increased risk for death over time, because the proportion of in-hospital deaths did not change during the study interval (1994 to 1996 versus 2002 to 2004: $12.3 \%$ versus $12.4 \% ; \mathrm{P}=1.00$ ).

To exclude under-reporting of HCV diagnoses as a cause of the observed increase in hospitalizations, a sensitivity analysis was conducted, assuming greater under-reporting during the early years of the interval (Figure 4). In the baseline scenario (in which 50\% of HCV cases were under-reported in 1994) the average annual increases in liver-related and all-cause HCV hospitalizations were $7.8 \%$ (95\% CI $5.8 \%$ to $9.7 \%$ ) and $15.7 \%$ (95\% CI $14.6 \%$ to $16.8 \%$ ), respectively. In the extreme

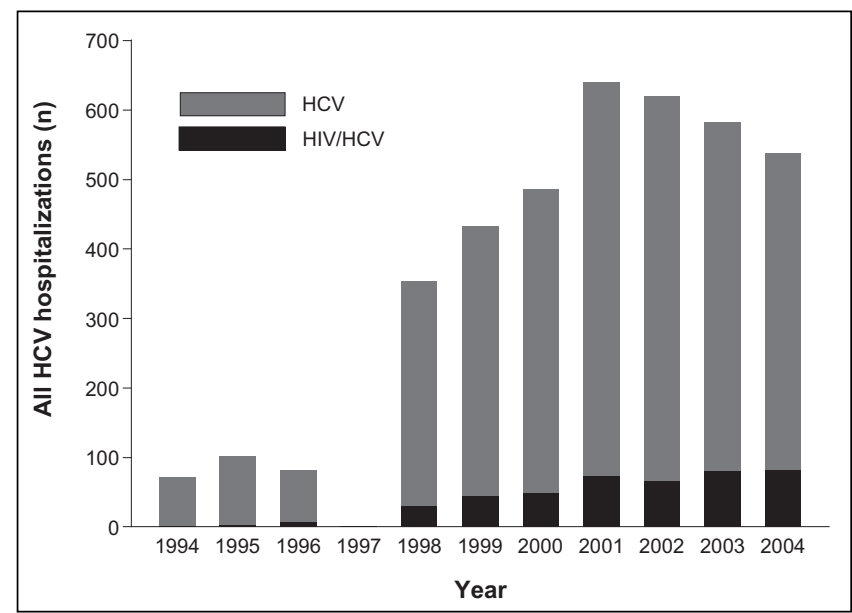

Figure 2) Annual number of hepatitis $\mathrm{C}$ virus (HCV) hospitalizations in the Calgary Health Region (1994 through 2004), stratified according to HIV status

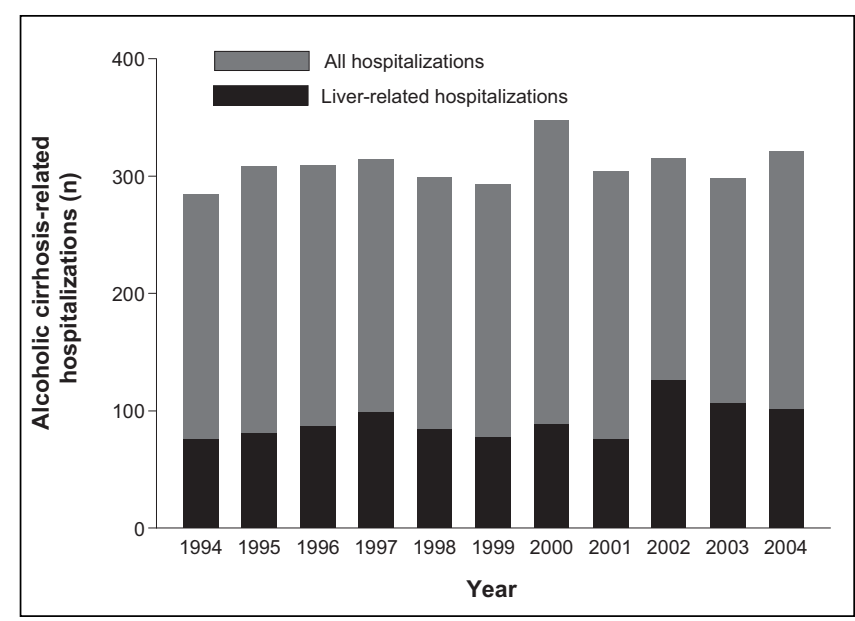

Figure 3) Annual number of alcoholic cirrhosis-related hospitalizations in the Calgary Health Region (1994 through 2004)

scenario of $75 \%$ under-reporting in 1994, the average annual increases in liver-related (1.5\%; 95\% CI $0.05 \%$ to $3.0 \%)$ and all-cause HCV hospitalizations (14.4\%; 95\% CI 13.3, 15.4\%) remained significant.

The hospitalization growth patterns that were observed were greatest among patients in their 40s and 50s (Table 1). While other patient subgroups demonstrated a decline in the number of hospitalizations during the study interval, patients in their 40s and 50s demonstrated an increase (Table 2). For example, comparing the periods 1994 to 1996 and 2002 to 2004, patients aged 40 to 59 years demonstrated an increase in HCV liver-related hospitalizations and hospital days from $49.1 \%$ to $65.4 \%(\mathrm{P}=0.002)$ and $53.0 \%$ to $65.0 \%(\mathrm{P}<0.0005)$, respectively.

Although men accounted for the majority of $\mathrm{HCV}$-related admissions (liver-related, 67.4\%; all cause, 59.2\%), women saw a disproportionate increase during the study interval. Liver-related and all-cause HCV hospitalizations increased by an average of $19.3 \%$ (95\% CI $14.6 \%$ to $24.2 \%$ ) and $21.3 \%$ 
TABLE 1

Average annual percentage growth rates in hepatitis C virus (HCV) and alcoholic cirrhosis hospitalizations, 1994 through 2004*

\begin{tabular}{|c|c|c|c|c|}
\hline \multirow[b]{2}{*}{ Outcome } & \multicolumn{4}{|c|}{ Average annual growth rate, $\%(95 \% \mathrm{CI})$} \\
\hline & 20 to 39 years of age & 40 to 59 years of age & $\geq 60$ years of age & All ages \\
\hline \multicolumn{5}{|c|}{ Liver-related HCV hospitalizations ( $\mathrm{n=869)}$} \\
\hline Hospitalizations & $6.9(1.5$ to 12.7$)$ & 19.1 (15.7 to 22.7$)$ & $12.3(7.3$ to 17.5$)$ & 15.1 (12.6 to 17.7$)$ \\
\hline Days in the hospital & $16.3(14.1$ to 18.4$)$ & 19.4 (18.4 to 20.4$)$ & $16.8(15.2$ to 18.3$)$ & $17.9(17.1$ to 18.7$)$ \\
\hline \multicolumn{5}{|c|}{ All-cause HCV hospitalizations $(n=4002)$} \\
\hline Hospitalizations & $17.0(15.0$ to 18.9$)$ & $24.0(22.0$ to 26.1$)$ & $14.4(11.0$ to 17.9$)$ & 19.2 (17.9 to 20.5$)$ \\
\hline Days in the hospital & $19.3(18.7$ to 20.0$)$ & $26.9(26.3$ to 27.5$)$ & $22.4(21.3$ to 23.5$)$ & $22.9(22.5$ to 23.4$)$ \\
\hline \multicolumn{5}{|c|}{ Liver-related alcoholic cirrhosis hospitalizations $(n=2387)$} \\
\hline Hospitalizations & $3.4(-1.4$ to 8.4$)$ & $-0.4(-2.1$ to 1.4$)$ & $-3.6(-5.7$ to -1.6$)$ & $-1.4(-2.7$ to -0.2$)$ \\
\hline Days in the hospital & 7.1 (5.6 to 8.6$)$ & $3.4(2.9$ to 4.0$)$ & $2.0(1.5$ to 2.5$)$ & $3.0(2.6$ to 3.4$)$ \\
\hline \multicolumn{5}{|c|}{ All-cause alcoholic cirrhosis hospitalizations $(n=3393)$} \\
\hline Hospitalizations & $4.8(0.1$ to 9.1$)$ & $1.2(0.3$ to 2.7$)$ & $-3.1(-4.7$ to -1.5$)$ & $-0.4(-1.4$ to 0.7$)$ \\
\hline Days in the hospital & 7.5 (6.1 to 8.8$)$ & $6.4(6.0$ to 6.9$)$ & $1.5(1.1$ to 1.9$)$ & 4.1 (3.8 to 4.4$)$ \\
\hline
\end{tabular}

${ }^{*}$ Patients younger than 20 years of age were excluded due to the small number of observations precluding regression analyses

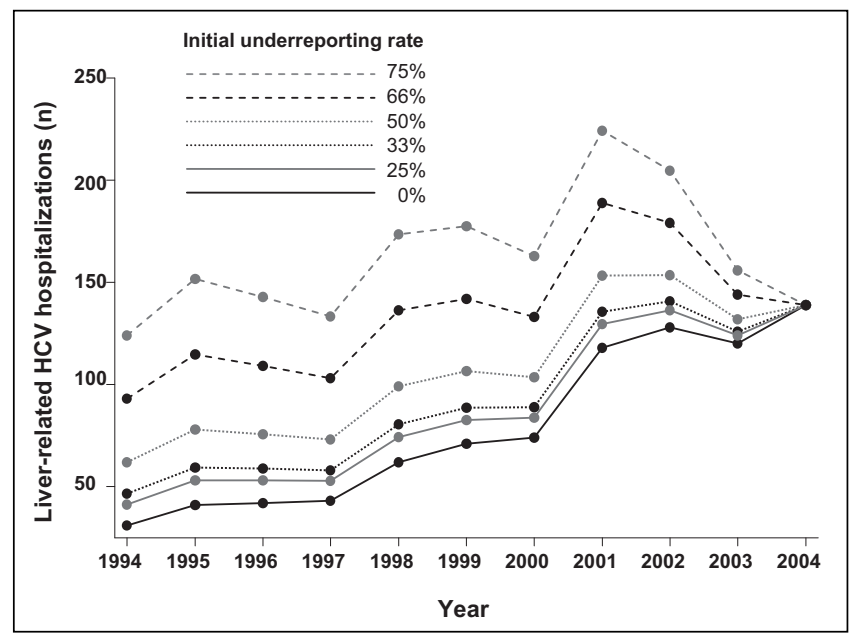

Figure 4) Sensitivity analysis regarding the under-reporting of hepatitis $\mathrm{C}$ virus (HCV) diagnoses during the early years of the study period. In the baseline scenario, 50\% of cases were under-reported in 1994; under-reporting fell by a fixed amount annually until all cases were reported in 2004. The initial under-reporting rate varied between 25\% and $75 \%$

(19.3\% to $23.4 \%$ ) annually in women, compared with $13.1 \%$ (95\% CI $10.1 \%$ to $16.2 \%$ ) and $17.7 \%$ (16.1\% to $19.3 \%)$, respectively in men $(\mathrm{P}<0.0005$ for comparisons of men and women). These increases persisted despite the exclusion of 229 pregnancy-related hospitalizations (ICD-9-CM 630-677 [19]; and ICD-10 000-O99 [20]; data not shown). Accordingly, the share of HCV hospitalizations (liver-related and all-cause) attributable to men decreased significantly between the 1994 to 1996 period and the 2002 to 2004 period (Table 2). As in the overall analysis, the greatest average annual increase in number of HCV hospitalizations among women was observed in the 40- to 59-year-old age group (Table 3). The average annual increase in liver-related hospitalizations was greatest in women 60 years of age and older (Table 3).

\section{HIV/HCV coinfection}

From 1994 through 2004, there were 442 hospitalizations (11.0\% of the total) among HIV/HCV coinfected patients. Thirty-six of these admissions $(8.1 \%)$ were liver-related; this proportion did not change significantly between the 1994 to 1996 period and the 2002 to 2004 period (8.3\% versus $10.0 \%$; $\mathrm{P}=0.85)$. Compared with their HIV-negative counterparts, HIV/HCV coinfected patients admitted for liver-related causes were younger (median age [IQR], 49.9 years [44.4 to 59.2 years] versus 40.2 years [37.1 to 47.6 years]; $\mathrm{P}<0.0005$ ) and a higher proportion were men $(66.4 \%$ versus $91.7 \%$; $\mathrm{P}=0.001)$. HIV coinfected patients also comprised an increasing share of liver-related and all-cause HCV hospitalizations in the final years compared with the initial years of the study period (Table 2). Average annual increases in liver-related (40.3\%; $95 \%$ CI $21.9 \%$ to $61.4 \%$ ) and all-cause HCV hospitalizations (29.3\%; $95 \%$ CI $24.8 \%$ to $34.0 \%$ ) in this patient subgroup were the highest of any observed (Figures 1 and 2). Accordingly, these patients had highly significant average annual increases in the lengths of stay for liver-related (37.7\%; 95\% CI 31.9\% to $43.8 \%$ ) and all-cause HCV admissions $(29.6 \%$; $95 \%$ CI $28.2 \%$ to $31.0 \%)$.

\section{DISCUSSION}

Our study demonstrates a highly significant increase in the burden of $\mathrm{HCV}$ on the health care system. For the primary outcomes of interest - liver-related hospitalizations, lengths of stay, and in-hospital mortality - we observed average annual increases ranging from $15 \%$ to $18 \%$. In contrast, alcoholic cirrhosis-related hospitalizations, costs and inpatient deaths remained stable. These results suggest that the future burden of HCV will likely surpass previous expectations. Zou et al (10) projected a doubling of the number of patients with HCVrelated complications, including liver-related deaths, between 1998 and 2008. Between 1994 and 2004, fourfold increases in liver-related HCV hospitalizations, lengths of stay and inpatient deaths were observed, suggesting that published projections of HCV burden may be conservative. Our results are in keeping with hospitalization data in the United States, which showed three- to fourfold increases in these outcomes between 
TABLE 2

Demographic characteristics of hepatitis C virus (HCV)-related hospitalizations*

\begin{tabular}{|c|c|c|c|c|c|c|}
\hline \multirow[b]{2}{*}{ Characteristic } & \multicolumn{3}{|c|}{ Liver-related HCV hospitalizations } & \multicolumn{3}{|c|}{ All-cause HCV hospitalizations } \\
\hline & 1994 to $1996(n=114)$ & 2002 to $2004(n=387)$ & $\mathbf{P}$ & 1994 to $1996(n=255)$ & 2002 to $2004(n=1,739)$ & $\mathbf{P}$ \\
\hline Men, \% (n) & $75.4(86)$ & $64.6(250)$ & 0.03 & $67.1(171)$ & $57.1(993)$ & 0.003 \\
\hline Age, years, median (IQR) & 46.0 (40.3 to 60.8$)$ & 50.7 (45.8 to 57.9$)$ & 0.004 & 42.7 (34.1 to 55.4$)$ & 44.9 (36.4 to 51.7$)$ & 0.06 \\
\hline \multicolumn{7}{|l|}{ Age group, years, $\%(n)$} \\
\hline$<20$ & $2.6(3)$ & $0.3(1)$ & 0.002 & $9.0(23)$ & $0.4(6)$ & $<0.0005$ \\
\hline 20 to 39 & $22.0(25)$ & $12.7(49)$ & & $33.7(86)$ & $34.6(601)$ & \\
\hline 40 to 59 & $49.1(56)$ & $65.4(253)$ & & $35.7(91)$ & $53.7(933)$ & \\
\hline$\geq 60$ & $26.3(30)$ & $21.7(84)$ & & $21.6(55)$ & $11.4(199)$ & \\
\hline HIV/HCV coinfection, \% (n) & $0.9(1)$ & $5.9(23)$ & 0.02 & $4.7(12)$ & $13.2(230)$ & $<0.0005$ \\
\hline
\end{tabular}

*Patients younger than 20 years of age were excluded due to the small number of observations precluding regression analyses. IQR Interquartile range

TABLE 3

Average annual percentage growth rates in hepatitis C virus (HCV) hospitalizations in women, 1994 through $2004^{*}$

\begin{tabular}{|c|c|c|c|c|}
\hline \multirow[b]{2}{*}{ Outcome } & \multicolumn{4}{|c|}{ Average annual growth rate, $\%(95 \% \mathrm{Cl})$} \\
\hline & 20 to 39 years of age & 40 to 59 years of age & $\geq 60$ years of age & All ages \\
\hline \multicolumn{5}{|c|}{ Liver-related HCV hospitalizations $(n=283)$} \\
\hline Hospitalizations & $12.9(5.1$ to 21.4$)$ & 20.9 (13.6 to 28.7$)$ & 25.6 (15.9 to 36.2$)$ & 19.3 (14.6 to 24.2 ) \\
\hline Days in the hospital & $25.4(22.2$ to 28.8$)$ & $18.2(16.3$ to 20.1$)$ & $25.3(22.3$ to 28.4$)$ & 21.4 (19.9 to 22.8$)$ \\
\hline \multicolumn{5}{|c|}{ All-cause HCV hospitalizations $(n=1633)$} \\
\hline Hospitalizations & 19.6 (16.8 to 22.5$)$ & $26.6(22.8$ to 30.4$)$ & $19.1(13.2$ to 25.2$)$ & 21.3 (19.3 to 23.4 ) \\
\hline Days in the hospital & $23.0(22.0$ to 24.0$)$ & 29.1 (28.0 to 30.2 ) & 25.2 (23.3 to 27.1$)$ & 25.6 (24.9 to 26.3 ) \\
\hline
\end{tabular}

*Patients younger than 20 years of age were excluded due to the small number of observations precluding regression analyses

1994 and 2001 (22). In this study, Grant et al (22) also reported a $26 \%$ annual growth rate for HCV-related hospital charges, which was slightly lower than the $41 \%$ annual increase in costs that we observed. Based on the costs and annual growth rates observed in the CHR, we project that liver-related HCV hospitalizations will cost the Canadian health care system approximately $\$ 240$ million in the year 2020 .

Our results are consistent with natural history studies describing the impact of age, sex and HIV coinfection on the progression of chronic HCV (4-7). The role of aging is highlighted by the disproportionate shares of hospitalizations among patients in their 40s and 50s, in whom average annual growth statistics ranging from $19 \%$ to $27 \%$ were observed. Because the prevalence of $\mathrm{HCV}$ is highest in this subgroup (26), aging of these patients will exact an increasing toll on the health care system in coming years. As expected, men contributed to a majority of HCV-related hospitalizations due to their higher HCV prevalence (26) and accelerated disease progression (4-7). Surprisingly, however, we observed a disproportionate increase in the number of hospitalizations among women - a previously unreported finding that warrants confirmation in larger studies. A sex-dependent difference in underreporting at the beginning of the interval (eg, less frequent testing in women due to their lower $\mathrm{HCV}$ prevalence) is a potential, but entirely speculative, explanation.

Finally, HIV/HCV coinfected patients experienced alarming annual growth rates, ranging from $30 \%$ to $40 \%$, for liverrelated and all-cause HCV hospitalizations. In an analysis of United States hospitalization data among HIV-infected patients, Gebo et al (27) described a 29\% reduction in overall hospitalizations, but a tripling of HCV-related hospitalizations between 1996 and 2000. Due to reductions in HIV-related mortality attributable to highly active antiretroviral therapy and prophylaxis of opportunistic pathogens, HCV has emerged as a major cause of morbidity and mortality in coinfected patients $(28,29)$. For example, in a nationwide population of HIV-infected patients in France (30), deaths due to end-stage liver disease - the majority of which were due to $\mathrm{HCV}$ - occurred in $1.5 \%$ of patients in 1995, 6.6\% in 1997, $14.3 \%$ in 2001 and $12.6 \%$ in 2003. We also found that HIV/HCV coinfected patients admitted for liver-related conditions were approximately 10 years younger than their HIV-negative counterparts, in keeping with the accelerated natural history of HCV in this subgroup $(6,7)$.

The increasing burden of chronic HCV that we have observed highlights the importance of primary prevention of $\mathrm{HCV}$ infections and initiating anti-HCV therapy in eligible patients. Currently available regimens consisting of peginterferon and ribavirin lead to viral eradication in approximately one-half of treated individuals $(31,32)$. Viral clearance has been associated with improved clinical outcomes, even in those who have already progressed to cirrhosis (33-35). Unfortunately, due to its cost, contraindications, toxicities, the requirement for intensive monitoring and counselling that is typically available in only specialized centres, and the reluctance of patients to undergo treatment, the widespread uptake of anti-HCV therapy has been limited (36-38). Of the roughly 200,000 prevalent cases in Canada, only an estimated 5000 are treated annually (2). In a recent study from a Canadian hepatology centre (38), only 29\% of 1317 patients were considered 
eligible for therapy, and of these, only $38 \%$ ( $11 \%$ of the total) actually received treatment. Hopefully, the more widespread dissemination of antiviral therapy, including more effective and better-tolerated agents under development (39), will be able to stem the coming tide of HCV-related morbidity and mortality, as suggested in modelling studies $(11,12,14,15)$.

Our study had several limitations. Most importantly, underreporting of $\mathrm{HCV}$ diagnoses during the early years of the study may have led to an overestimation of the true increase in the burden of HCV. Several points argue against the significance of this limitation. First, we observed parallel increases in allcause and liver-related HCV outcomes. Although underreporting is conceivably more likely in patients admitted for nonhepatic conditions, it is much less likely that patients with liver-related admissions would not be tested for HCV or have the diagnosis recorded in their discharge abstract. Second, greater annual increases in liver-related HCV hospitalizations were observed among 40- to 59-year-olds than among older patients. There is no evidence to suggest an age-dependent effect on under-reporting of HCV. Finally, our sensitivity analysis supported the robustness of our findings. In every scenario, including the most extreme in which $75 \%$ of cases were under-reported in 1994, increases in liver-related HCV admissions remained significant. Our study was also limited by the inability to track individual patients over time. Thus, we cannot distinguish changes in overall hospitalization counts from the numbers of hospitalizations per patient. Finally, our data

\section{REFERENCES}

1. Hepatitis C - global prevalence (update). Wkly Epidemiol Rec 2000;75:18-9.

2. Sherman M, Shafran S, Burak K, et al. Management of chronic hepatitis C: Consensus guidelines. Can J Gastroenterol 2007;21(Suppl C):25C-34C.

3. Thomas DL, Seeff LB. Natural history of hepatitis C. Clin Liver Dis 2005;9:383-98, vi.

4. Poynard T, Bedossa P, Opolon P. Natural history of liver fibrosis progression in patients with chronic hepatitis C. The OBSVIRC, METAVIR, CLINIVIR, and DOSVIRC groups. Lancet 1997;349:825-32.

5. Poynard T, Ratziu V, Charlotte F, Goodman Z, McHutchison J, Albrecht J. Rates and risk factors of liver fibrosis progression in patients with chronic hepatitis C. J Hepatol 2001;34:730-9.

6. Benhamou Y, Bochet M, Di Martino V, et al. Liver fibrosis progression in human immunodeficiency virus and hepatitis $\mathrm{C}$ virus coinfected patients. The Multivirc Group. Hepatology 1999;30:1054-8.

7. Graham CS, Baden LR, Yu E, et al. Influence of human immunodeficiency virus infection on the course of hepatitis $\mathrm{C}$ virus infection: A meta-analysis. Clin Infect Dis 2001;33:562-9.

8. Pohani G, Zou S, Tepper M. Trends of hepatitis B and hepatitis C mortality in Canada, 1979-1997. Can J Public Health 2001;92:250-4

9. Verna EC, Brown RS Jr. Hepatitis $C$ virus and liver transplantation. Clin Liver Dis 2006;10:919-40.

10. Zou S, Tepper M, El Saadany S. Prediction of hepatitis $C$ burden in Canada. Can J Gastroenterol 2000;14:575-80.

11. Davis GL, Albright JE, Cook SF, Rosenberg DM. Projecting future complications of chronic hepatitis $\mathrm{C}$ in the United States. Liver Transpl 2003;9:331-8.

12. Deuffic-Burban S, Poynard T, Sulkowski MS, Wong JB. Estimating the future health burden of chronic hepatitis $\mathrm{C}$ and human immunodeficiency virus infections in the United States. J Viral Hepat 2007;14:107-15.

13. Wong JB, McQuillan GM, McHutchison JG, Poynard T. Estimating future hepatitis $\mathrm{C}$ morbidity, mortality, and costs in the United States. Am J Public Health 2000;90:1562-9.

14. Buti M, San Miguel R, Brosa M, et al. Estimating the impact of hepatitis $\mathrm{C}$ virus therapy on future liver-related morbidity, mortality and costs related to chronic hepatitis C. J Hepatol 2005;42:639-45. originates from a single, albeit large, Canadian health region. The generalizability of our findings to other regions (within Canada and elsewhere) requires confirmation.

Shortly following its discovery, HCV was described as "a sleeping giant" (40); our data support previous findings that the giant has indeed awoken (22). We observed highly significant increases in HCV-related hospitalizations, lengths of stay, hospital costs and in-hospital deaths that likely foreshadow an even greater burden on the health care system. To stem this tide, health care policy makers and physicians must focus on preventive initiatives and strategies to maximize the dissemination and most effective use of potentially curative therapies.

CONTRIBUTIONS: Robert Myers conceived the study, performed the statistical analyses and wrote the first draft of the manuscript. MingFu Liu extracted administrative data. Abdel Aziz Shaheen performed the validation study and assisted with statistical analyses. All authors contributed to revising the manuscript and approved the final version. Robert Myers is the guarantor of the study.

ACKNOWLEDGEMENTS: Robert Myers holds a Clinical Investigator Award from the Alberta Heritage Foundation for Medical Research.

COMPETING INTERESTS: None declared.
15. Deuffic-Burban S, Wong JB, Valleron AJ, Costogliola D, Delfraissy JF, Poynard T. Comparing the public health burden of chronic hepatitis C and HIV infection in France. J Hepatol 2004;40:319-26.

16. Alter HJ, Purcell RH, Shih JW, et al. Detection of antibody to hepatitis $C$ virus in prospectively followed transfusion recipients with acute and chronic non-A, non-B hepatitis. N Engl J Med 1989;321:1494-500.

17. elSaadany S, Tepper M, Mao Y, Semenciw R, Giulivi A. An epidemiologic study of hepatocellular carcinoma in Canada. Can J Public Health 2002;93:443-6.

18. Alberta Health and Wellness. Data Disclosure Handbook. Alberta Health and Wellness, 2003:1-15.

19. International Classificiation of Diseases, 9th Revision, Clinical Modification (ICD-9-CM). Los Angeles: Practice Management Information Corporation, 2001.

20. Canadian Classification of Health Interventions (ICD-10-CA). Ottawa: Canadian Institute for Health Information, 2006.

21. Kim WR, Gross JB Jr, Poterucha JJ, Locke GR III, Dickson ER. Outcome of hospital care of liver disease associated with hepatitis C in the United States. Hepatology 2001;33:201-6.

22. Grant WC, Jhaveri RR, McHutchison JG, Schulman KM, Kauf TL. Trends in health care resource use for hepatitis $\mathrm{C}$ virus infection in the United States. Hepatology 2005;42:1406-13.

23. Kuo G, Choo QL, Alter HJ, et al. An assay for circulating antibodies to a major etiologic virus of human non-A, non-B hepatitis. Science 1989;244:362-4.

24. Cameron AC, Trivedi PK. Regression Analysis of Count Data. New York: Cambridge University Press, 1998.

25. Statistics Canada. Consumer Price Index. Ottawa: Statistics Canada, 2003. <http://www43.statcan.ca/03/03a/03a_005b_e.htm> (Version current at February 19, 2008).

26. Armstrong GL, Wasley A, Simard EP, McQuillan GM, Kuhnert WL, Alter MJ. The prevalence of hepatitis $\mathrm{C}$ virus infection in the United States, 1999 through 2002. Ann Intern Med 2006;144:705-14.

27. Gebo KA, Diener-West M, Moore RD. Hospitalization rates differ by hepatitis $\mathrm{C}$ satus in an urban HIV cohort. J Acquir Immune Defic Syndr 2003;34:165-73.

28. Jaggy C, von Overbeck J, Ledergerber B, et al. Mortality in the Swiss HIV Cohort Study (SHCS) and the Swiss general population. Lancet 2003;362:877-8. 
29. Qurishi N, Kreuzberg C, Luchters G, et al. Effect of antiretroviral therapy on liver-related mortality in patients with HIV and hepatitis C virus coinfection. Lancet 2003;362:1708-13.

30. Rosenthal E, Pialoux G, Bernard N, et al. Liver-related mortality in human-immunodeficiency-virus-infected patients between 1995 and 2003 in the French GERMIVIC Joint Study Group Network (MORTAVIC 2003 Study). J Viral Hepat 2007;14:183-8.

31. Fried MW, Shiffman ML, Reddy KR, et al. Peginterferon alfa-2a plus ribavirin for chronic hepatitis $\mathrm{C}$ virus infection. $\mathrm{N}$ Engl J Med 2002;347:975-82.

32. Manns MP, McHutchison JG, Gordon SC, et al. Peginterferon alfa$2 \mathrm{~b}$ plus ribavirin compared with interferon alfa- $2 \mathrm{~b}$ plus ribavirin for initial treatment of chronic hepatitis C: A randomised trial. Lancet 2001;358:958-65.

33. Yoshida H, Arakawa Y, Sata M, et al. Interferon therapy prolonged life expectancy among chronic hepatitis $\mathrm{C}$ patients. Gastroenterology 2002;123:483-91.

34. Yoshida H, Shiratori Y, Moriyama M, et al. Interferon therapy reduces the risk for hepatocellular carcinoma: national surveillance program of cirrhotic and noncirrhotic patients with chronic hepatitis
C in Japan. IHIT Study Group. Inhibition of Hepatocarcinogenesis by Interferon Therapy. Ann Intern Med 1999;131:174-81.

35. Yu ML, Lin SM, Chuang WL, et al. A sustained virological response to interferon or interferon/ribavirin reduces hepatocellular carcinoma and improves survival in chronic hepatitis C: a nationwide, multicentre study in Taiwan. Antivir Ther 2006;11:985-94.

36. Falck-Ytter Y, Kale H, Mullen KD, Sarbah SA, Sorescu L, McCullough AJ. Surprisingly small effect of antiviral treatment in patients with hepatitis C. Ann Intern Med 2002;136:288-92.

37. Muir AJ, Provenzale D. A descriptive evaluation of eligibility for therapy among veterans with chronic hepatitis $\mathrm{C}$ virus infection. J Clin Gastroenterol 2002;34:268-71.

38. Moirand R, Bilodeau M, Brissette S, Bruneau J. Determinants of antiviral treatment initiation in a hepatitis $\mathrm{C}$-infected population benefiting from universal health care coverage. Can J Gastroenterol 2007;21:355-61.

39. Pawlotsky JM, Gish RG. Future therapies for hepatitis C. Antivir Ther 2006;11:397-408.

40. Alter MJ. Hepatitis C: A sleeping giant? Am J Med 1991;91(Suppl 3B):112S-115S 


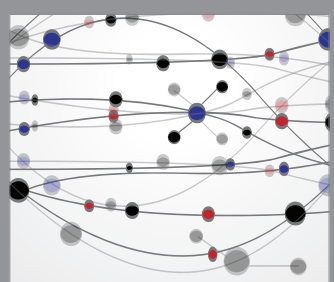

The Scientific World Journal
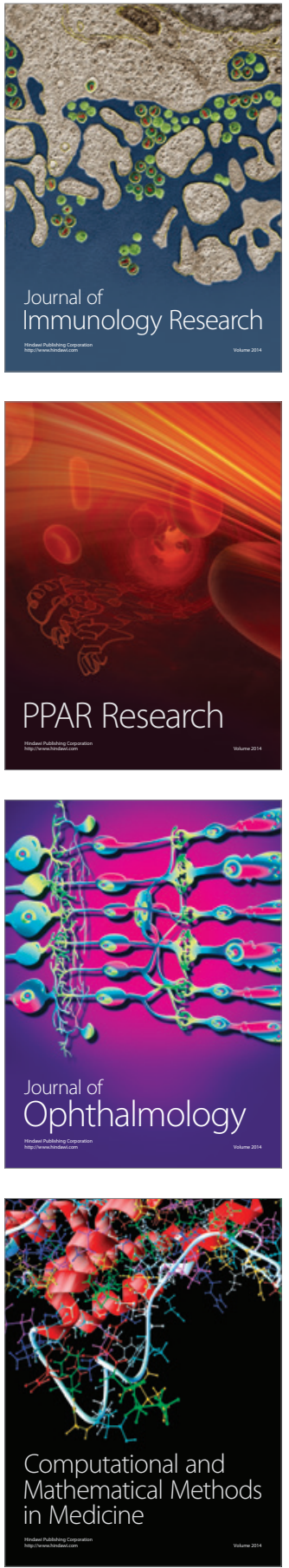

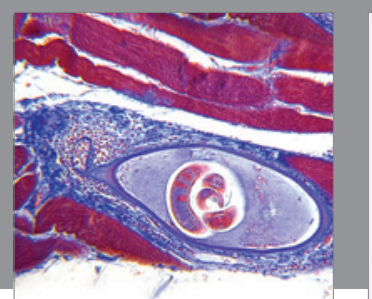

Gastroenterology Research and Practice

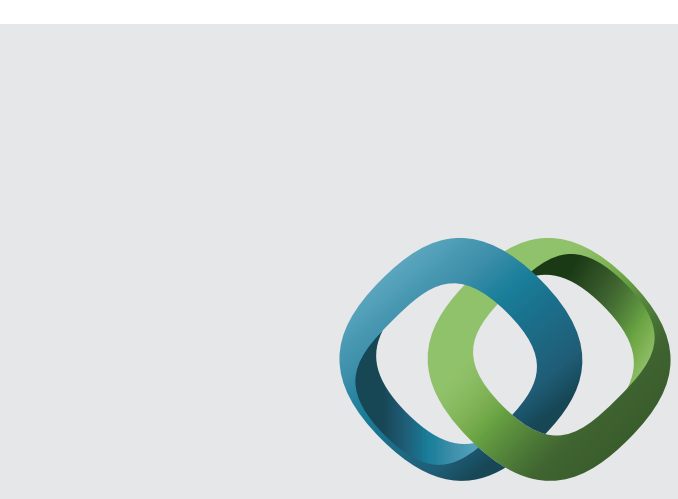

\section{Hindawi}

Submit your manuscripts at

http://www.hindawi.com
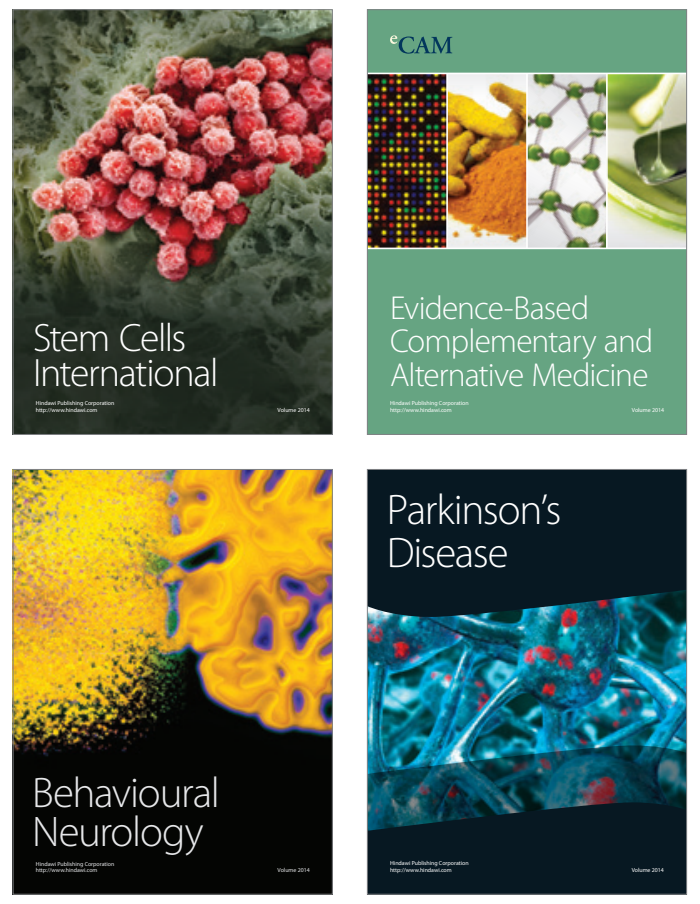
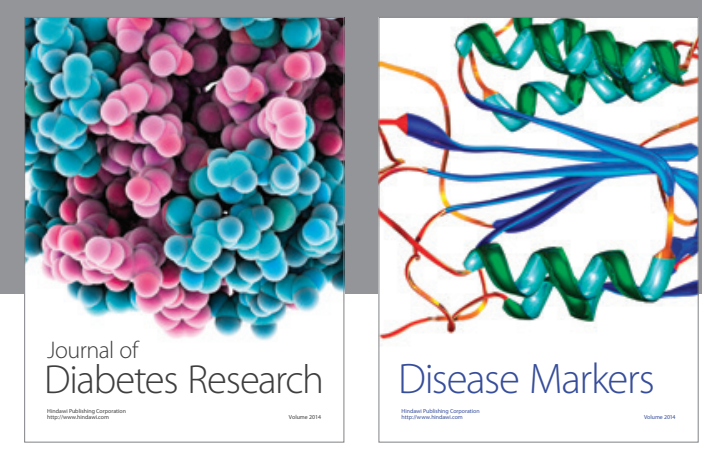

Disease Markers
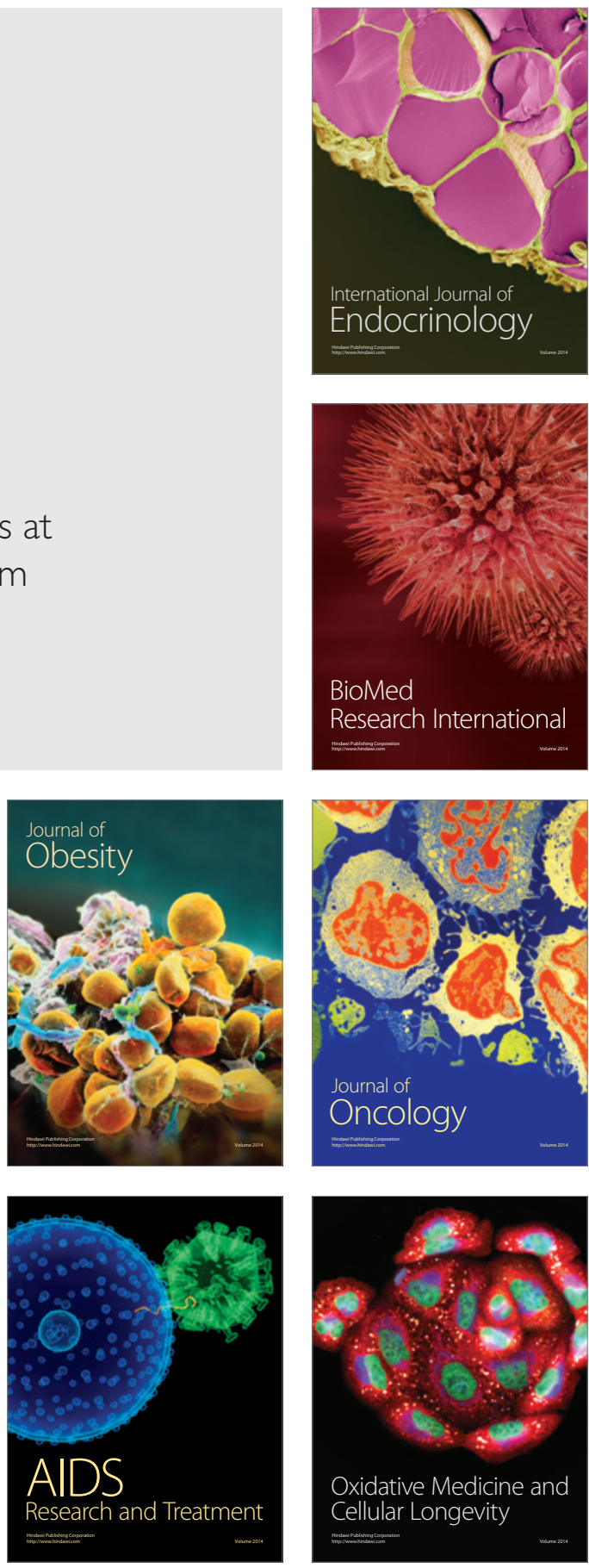